\title{
Listening to Air Quality
}

\author{
Sunyoung Kim and Eric Paulos \\ Carnegie Mellon University, 5000 Forbes Ave, Pittsburgh, PA 15213 \\ sunyoung.kim@cs.cmu.edu
}

\begin{abstract}
In most large cities of the developing world, urban air pollution has worsened, which has been detrimental to the health of their populations. At the same time, it is difficult for lay people to sense the level of air quality with bare human perception as air pollutants are mostly invisible and odorless. We believe that computing technologies can help increase awareness of urban air quality. To the end, we designed and implemented an application that provides users a sense of the air quality level in a sensory input, audio signal, expecting that our system can help increase awareness of air quality. By using our system regularly, we expect that people can easily interpret and understand the level of air quality in surroundings.
\end{abstract}

\section{INTRODUCTION}

Urban air pollution is higher in developing countries because they often depend more upon coal and oil, considered the "dirtiest" of energy sources, for heating, cooking, and other activities [5]. Fuel combustion by motor vehicles is another major contribution to poor air quality in urban areas. These emissions are particularly detrimental to human health because pollutants are emitted at ground level. Motor vehicles in developing countries cause serious air pollution because they are concentrated in a few large cities, many are in poor mechanic condition, and few emission standards exist [3].

We believe that it is crucial to raise awareness of the level of air quality in one's surroundings, as many air pollutants that are imperceptible to us are harmful, and in some cases, fatal. In this work we propose a simple technology to convert the level of air quality into ambient sound that augments the music of an existing portable music player, the iPod Touch. An auditory representation of the level of air quality is chosen to see the possibility of other ambient representation of air quality besides visual cues. In general, people do not think about public space's air quality while it is very common for people to listen to music when they are in public places such as when waiting a bus or subway, walking on the street, or reading books in a park. We thought it would be interesting to merge important but rather ignored information regarding our environment into our daily lives. If we can prove that auditory information is effective in raising a user's awareness about air quality, the representation platform could be transformed from a personal device to public utilities with auditory output (e.g., radio signals) for public awareness for urban air quality. Among various types of air pollutants, we decided to measure carbon monoxide because it is known as one of the most serious air pollution contributors, ${ }_{2}$ especially in developing countries [5]. Next, we will describe carbon monoxide more in detail.

We designed and implemented an application that provides users a sense of the air quality level as an audio signal, with the expectation that our system can help increase awareness of air quality. For the proof of concept, we chose the iPod touch as a platform of this system. However, any smart phone or music player that allows third party applications would work.

\section{AIR POLLUTANT: CARBON MONOXIDE (CO)}

Carbon monoxide is a colourless, odourless and toxic gas. It is known as a major atmospheric pollutant in urban areas, chiefly from exhaust of internal combustion engines including vehicles, portable and back-up generators, lawn mowers, but also from improper burning of various other fuels including wood, coal, charcoal, oil, kerosene, propane, natural gas, and trash [5]. Carbon monoxide results from incomplete combustion of fuel and is emitted directly from vehicle tailpipes. At low levels of exposure, $\mathrm{CO}$ causes mild effects that are often mistaken for the flu. These symptoms include headaches, dizziness, disorientation, nausea and fatigue [2]. The effects of CO 
exposure can vary greatly from person to person depending on age, overall health and the concentration and length of exposure.

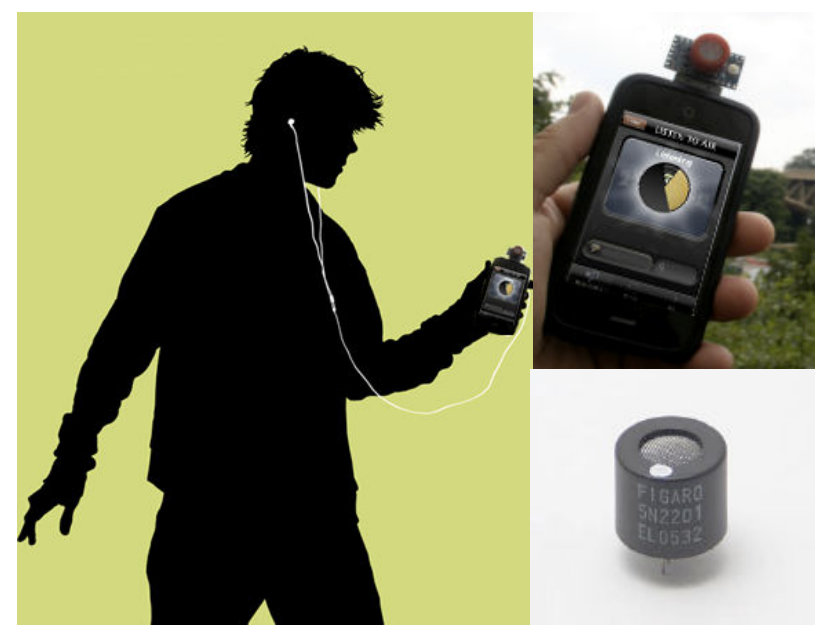

Figure 1: System Mockups (the original image at the left from Apple()) and TGS2201 CO Sensor (right bottom)

\section{RELATED WORKS}

There have been a few efforts to measure urban air quality from various angles. Aoki et al. developed mobile sensing platforms to collect urban air quality data deployed on street sweeping vehicles [1], and Tirabassl explored ways to predict urban air pollution with street noise levels [4]. Our approach is aimed at providing people a sense of air quality in an easily interpretable manner by auditory output than sensing technology itself.

Ambient Addition [6] is similar to our design in concept, converting environmental status to sound and superimposing it on the existing sound. Vawter created a Walkman with binaural microphones that analyzes microphone's sound and superimposes a layer of harmony and rhythm on top of the listener's world. The main difference is that we sensed the air quality to convert into sound while Ambient Addition captured environmental noise and converted to sound.

\section{SYSTEM IMPLEMENTATION}

Our system consists of two parts. First, we built a music player application that runs on the iPhone OS. As a separate unit, we built a CO sensor using Figaro TGS2201 semiconductor carbon monoxide sensor (see Figure 1, bottom right) to be connected to an iPhone via serial jack. Then, the music player application reads the current level of air quality from the $\mathrm{CO}$ sensor unit and converts to musical rhythm superimposed onto the existing music.

The first part, a music player application, is not different from ordinary music player applications running on iPhone. When the second part, the $\mathrm{CO}$ sensor is connected to iPhone, the application starts to read the level of carbon monoxide in air. If the level of carbon monoxide exceeds a certain level that can cause effects to human health, the application starts to add an ambient buzzing sound on the top of currently playing musical sound. The level of carbon monoxide in air controls the volume of the ambient but subtle buzzing sound.

The biggest challenge will be figuring out the right type of sound that is to be subtle enough not to disturb a user's main activity, listening to music, while to be significant enough to notice changes in air quality by listening.

\section{PRELIMINARY RESULTS}

This work is still in progress. Thus, we do not have an empirical result yet. However, since the output is easy to interpret by lay people, we expect our system can increase awareness of air quality. 


\section{REFERENCES}

1. Aoki, P. M., Honicky, R. J., Mainwaring, A., Myers, C. Paulos, E. Subramanian, S. Woodruff, A., A vehicle for research: using street sweepers to explore the landscape of environmental community action. ACM SIGCHI 2009

2. Clean Air Trust, http://www.cleanairtrust.org/

3. The World Bank, http://www.worldbank.org

4. TirabassI, T., New directions: Listening out for urban air pollution, Atmospheric Environment 33 (1999) 4219-4220

5. US Environmental Protection Agency, http://www.epa.gov

6. Vawter, N., Ambient Addition, http://web.media.mit.edu/ nvawter/thesis/index.html 